Discussion Paper No. 04-21

\title{
The Subtraction Rule and its Effects on Pricing in the Electricity Industry
}

Walter Elberfeld

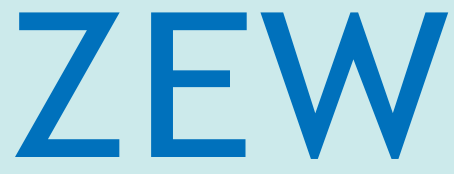

Zentrum für Europäische Wirtschaftsforschung $\mathrm{GmbH}$

Centre for European

Economic Research 
Discussion Paper No. 04-21

\title{
The Subtraction Rule and its Effects on Pricing in the Electricity Industry
}

\author{
Walter Elberfeld
}

Download this ZEW Discussion Paper from our ftp server:

\author{
ftp://ftp.zew.de/pub/zew-docs/dp/dp0421.pdf
}

Die Discussion Papers dienen einer möglichst schnellen Verbreitung von neueren Forschungsarbeiten des ZEW. Die Beiträge liegen in alleiniger Verantwortung der Autoren und stellen nicht notwendigerweise die Meinung des ZEW dar.

Discussion Papers are intended to make results of ZEW research promptly available to other economists in order to encourage discussion and suggestions for revisions. The authors are solely responsible for the contents which do not necessarily represent the opinion of the ZEW. 


\section{Non-Technical Summary}

On April 19, 2001, the cartel offices published the report from the ,working group security of supply in service of the cartel offices of the federal republic and the states" about

1. the coverage from the intervention norms according to the antitrust regulations in inspecting the level of network access charges for power supply usage, and

2. the relevance of the antitrust regulation of impeding behavioral patterns shown by electricity network owners in relation of network access."

The report contains a basic statement of the cartel offices relating to the appropriateness of the level of network access charges as well as to impeding behavioral patterns of integrated network owners in the electricity industry. Of particular importance in this report is the socalled subtraction rule (S-rule), which has been proposed to improve the verification of improperly inflated network access charges. Under this rule the cartel office would calculate the difference between the network owner's price charged to the consumers and overall marginal costs of a rival, including network access charges, which the competitor has to pay to the network owner. If this value is negative, it would be concluded that network access charges are improperly inflated.

The present paper analyzes the proposed rule within a simple Hotelling-framework. Two states are compared; one state in which the S-rule is implemented, and one where it is not. The S-rule changes the network owner's incentives. Pricing below the rival's marginal costs would violate the S-rule, triggering a sanction. By increasing his price the network owner can reduce or avoid the sanction. If the network owner increases his price, the rival will follow suit, since reaction functions are upward sloping. Indeed, if the network owner's marginal costs are moderately or much lower than those of his rival, this is what will happen so that the S-rule would lead both firms to charge higher prices, making all consumers worse off. However, if the network owner is only slightly more or less efficient, then the introduction of the S-rule does not affect firms' behavior, and prices will remain unchanged. 


\title{
The subtraction rule and its effects on pricing in the electricity industry
}

\author{
Walter Elberfeld*
}

February 2004

\begin{abstract}
The paper deals with the subtraction rule, which has been proposed by the „working group security of supply in service of the cartel offices of the federal republic and the states" as an instrument to identify improperly inflated network access charges in the electricity industry. We analyze firms' price responses and adaptations to this rule. The results suggest that the introduction of the subtraction rule would increase prices, regardless of whether network access charges are improperly inflated or not.
\end{abstract}

Keywords: Electricity market, network access charges, abuse of a dominant position JEL-Classification: L43

Address: Centre for European Economic Research (ZEW)

Department of Industrial Economics and International Management

P.O.Box 103443

68304 Mannheim

Germany

Phone: $++49 / 621 / 1235-179$

Fax: $\quad++49 / 621 / 1235-170$

e-mail: elberfeld@,zew.de

* I would like to thank Professor C. C. von Weizsäcker for very helpful comments. 


\section{Introduction}

On April 24, 1998, Germany implemented the EU Electricity Market Directive from 1996 into a new energy law, the Energiewirtschaftsgesetz (EnWG). With this legal change, Germany opened its market fully to competition, ending the era of regional monopolies protected by demarcation agreements. Under the new law, each consumer is allowed to choose from a wide range of different suppliers. However, various complaints from new suppliers and consumers suggest that certain problems are still present. Especially, complaints about high network access charges indicate that these might be improperly inflated. Therefore, the „working committee security of supply in service of the cartel offices of the federal republic and the states " (Arbeitsauschuss Versorgungssicherheit der Kartellbehörden des Bundes und der Länder) appointed at its meeting on October 12/13, 2000 in Mainz the „working group electricity network utilization of the antitrust divisions of the federal republic and the states" (Arbeitgruppe Netznutzung Strom der Kartellbehörden des Bundes und der Länder) to examine the submitted reprovals and to work out a concept for coordinating the procedures among the antitrust divisions of the federation and the federal states. In their report $^{1}$ (dated Bonn, April 19, 2001), the working group suggested a certain rule, the subtraction rule (in the following we will refer to this rule as the S-rule), which should help to improve the verification of improperly inflated network access charges. The working group describes the S-rule as follows: „From the gross-retail price of electricity (kilowatt-hour rate plus demand rate allocated to the $\mathrm{kWh}$ ) for an integrated electric utility one deducts the netuser fee and the statutory predetermined duties (electricity tax, sales tax, concession levies). The remaining balance constitutes the - predominantly variable - costs for procurement of electricity and distribution (net-price of electricity). The so computed costs for the acquisition of electricity and retailing can then be compared with the market prices for the procurement of electricity or the costs of procurement for electricity of other energy supply companies, as well as with the retailing costs of comparable electric utilities (because a market price doesn't exist). [...] If the so determined costs for procurement and distribution considerably exceed the market prices, or the average costs incurred by other electric utilities, respectively, this will indicate that the integrated electric utility knowingly charges high network usage fees in order to make third party access difficult. In the presence of a combination of high network usage fees and very low assessed procurement and retailing costs of electricity, a strong indication for the inappropriateness of the charged network usage fee exists. Although these findings alone may not suffice for the ascertainment of inappropritate fees in terms of $\S 19$ paragraph 4 no. $4 \mathrm{GWB}$, they are, however, suitable to support the result of an inappropriate pricing found in the context of the treatment of comparisons." (p. 25f.)

The recently decided TEAG-case (B11-45/01) demonstrates that the Bundeskartellamt is indeed willing to apply the S-rule in order to find out whether network owners demand improperly inflated nework access charges. Although the TEAG-decision is mainly based on a cost enquiry, the cartel office has also calculated the price and cost elements of the S-rule and concludes that the result points into the same direction as the result of the cost analysis (see B11-45/01, p. 33). Since the wording in the text is quite cautious, one gets the impression that the cartel office itself is not sure, yet, whehter the S-rule can serve the

\footnotetext{
1 Report about 1. the coverage from the intervention norms according to the antitrust regulations in inspecting the level of network access charges for power supply usage, and 2. the relevance of the antitrust regulation of impeding behavioral patterns shown by electricity network owners in relation of network access."

(Bericht über die 1. Reichweite der kartellrechtlichen Eingriffsnormen für die Überprüfung der Höhe des Entgelts für die Nutzung der Stromnetze, and 2. die kartellrechtliche Relevanz von den Netzzugang behindernden Verhaltensweisen der Stromnetzbetreiber.)

${ }^{2}$ The text refers to this rule as the „Subtraktions-/Vergleichsmethode (bezüglich der Kostenbestandteile).
} 
intended purpose. In the present paper, we will argue that the S-rule should not be introduced. We will show that the implementation of the S-rule entails a strong tendency to increase prices. Using a Hotelling (1929)-type duopoly model, we develop this result by comparing two states; one state in which the S-rule is implemented, and one where it is not.

Section 2 contains the basic framework, and derives equilibrium prices when the S-rule is not implemented. Section 3 derives equilibrium prices when the S-rule is implemented. In Section 4 we analyse several alternative response strategies, by which network owner may react to the introduction of the S-rule. Finally, Section 5 concludes. All proofs are relegated to an appendix.

\section{The basic framework}

First of all, it is important to notice that electricity is not a homogenous good in the economic sense of the word. Though electricity is a highly standardized product from a technical point of view, and therefore may be seen as a homogeneous good in a physical sense, it is not homogenous in the economic sense. It already starts with consumers' preferences for certain types of primary energy usage. Some people prefer electricty generated from renewable energy sources instead of nuclear power, some desire electricity generated from municipal suppliers, and still others prefer electricity from "newcomers" in order to promote competition. In these cases, we talk about ideal preferences. They are very distinctive only with a minority of consumers. Much more important is the fact that consumers possess a distinct preference for a reliable supply. Though a large part of the services guaranteeing the reliability of supply is automatically covered by certain supplementary services, the perception of the consumer is that some suppliers are more reliable than others. Moreover, there are some extra services which are offered by some firms and not by others. In many cases, the personnel from the supplier's retail division maintains face-to-face contact with larger customers, thereby, influencing their decision making. Therefore, the selling of electricity concerns in all its particulars a market with differentiated products. Consequently, we will model the electricity market as a differentiated product market.

The formal structure of the model is as follows. There is a continuum of consumers $\phi$. They are uniformely distributed in terms of tastes on a line of potential products of length one, e.g., $\phi \in[0,1]$. We assume that a consumer's preferences can be described by

$$
U_{\phi}\left(p_{i}\right)=r-t\left(\phi-\phi_{i}\right)^{2}-p_{i},
$$

where $p_{i}$ denotes the price of variety $\phi_{i}$. The term $t\left(\phi-\phi_{i}\right)^{2}$ represents the disutility (in money units), which a consumer experiences, if he buys $\phi_{i}$ instead of his most preferred variety $\phi$. The parameter $r$ describes the utility from consuming $\phi$. In the following we assume that $r$ is large in the sense that every consumer will purchase one or the other variety, e.g., we assume that the market is fully covered. This assumption is very likely to be fulfilled in the electricity market, given observed prices and the willingness to pay for electricity.

The demand side of the model presupposes that demand is price inelastic, and that each consumer buys exactly one unit of electricity. The latter assumption means that we consider a kind of ,standardized“ customer. This perception requires that a real customer buying only half of that quantity has to be considered as a "half" customer, and a customer buying 100 times more than the standardized customer has to be viewed as „100 customers“. Of course, in practice a large customer will behave differently than 100 small customers buying the same 
amount, and indeed, this distinction may become important if one enters into a detailed investigation of the abuse of a dominant market position. However, at our level of abstraction ignoring the differences between small and large customers is insubstantial. The notion of a standardized customer implies that the sales of a firm coincide with the number of (standardized) customers.

There are two firms, $A$ and $B$, supplying some region with electricity. The varieties offered are $\phi_{A}$ and $\phi_{B}$, respectively, with $\phi_{A}, \phi_{B} \in[0,1]$. Without loss of generality, we assume that $\phi_{A}<\phi_{B}$. Moreover, we assume that $\phi_{A}=1-\phi_{B}$, which means that product differentiation advantages are symmetric. This assumption together with the inequality $\phi_{A}<\phi_{B}$ implies that $\left.\phi_{A} \in\right] 0,1 / 2\left[\right.$ and $\left.\phi_{B} \in\right] 1 / 2,1[$.

A consumer who is indifferent between the two firms is located at $\bar{\phi}=d_{A}\left(p_{A}, p_{B}\right)$, where $\bar{\phi}$ is obtained by equating utilities, e.g., $U_{\phi}\left(p_{A}\right)=U_{\phi}\left(p_{B}\right)$. With $T=t\left(2 \phi_{B}-1\right)$, firms ${ }^{6}$ respective demands can be written as

$$
d_{i}\left(p_{A}, p_{B}\right)=\bar{\phi}=\frac{1}{2}\left(1+\frac{p_{j}-p_{i}}{T}\right), i \neq j, i, j=A, B
$$

In Germany, network owners are to a large extent vertically integrated with generation and retail supply services. At the same time, they have to provide transmission services to any competing supplier. According to this ownership structure, we assume that one firm (firm $A$ ) is a new firm, which entered the market after deregulation, while $B$ is vertically integrated and owns the distribution network and power producing facilities. Let $r_{A}$ denote the network usage price charged by $B$, and denote the variable (constant) unit costs of network usage by $r_{B}$. Each firm is able to satisfy its demand either by generating electricity with own power plants or by buying electricity on the wholesale market. Denote $i$ 's variable (constant) unit procurement costs by $c_{i}, i=A, B$. Variable (constant) unit retail supply costs are denoted by $v_{i}, i=A, B$.

With this notation firms' profit functions can be expressed as

$$
\Pi_{i}\left(p_{A}, p_{B}\right)=\frac{1}{2}\left(p_{i}-m_{i}\right)\left(1+\frac{p_{j}-p_{i}}{T}\right)
$$

where $m_{i}=r_{i}+c_{i}+v_{i}$ are $i$ 's overall marginal costs, $i \neq j, i, j=A, B$. The first order conditions yield the reaction functions

$$
p_{i}\left(p_{j}\right)=\frac{m_{i}+p_{j}+T}{2}
$$

In equilibrium firm $i$ sets the price

$$
p_{i}^{*}=\frac{1}{3}\left(2 m_{i}+m_{j}\right)+T
$$


Note that prices increase with the degree of product differentiation $\phi_{B}-\phi_{A}=2 \phi_{B}-1$. Indeed, if $\phi_{B}-\phi_{A}$ increases, $T$ increases, implying a higher price of each firm. Firm i's output is given by

$$
q_{i}^{*}=\frac{m_{j}-m_{i}+3 T}{6 T}
$$

To avoid corner solutions, we assume that $\left|m_{B}-m_{A}\right|<3 T$. Equilibrium profits can be computed as

$$
\Pi_{i}^{*}=\frac{\left(m_{j}-m_{i}+3 T\right)^{2}}{18 T} .
$$

In principle, the distribution network provides its owner with a tool to practice market foreclosure. In a completely deregulated market the network owner could refuse to provide access to rival suppliers, or equivalently may engage in a price squeeze (e.g., charge them an exorbitant price). The final price then would be close to the monopoly level. In order to prevent such an outcome the price of network usage has to be regulated in some way. The German approach to solving the network pricing problem is based on the so-called negotiated third party access model. It leaves the detailed regulation of network access and transmission pricing to be negotiated by the different associations in the electricity industry. The results of these talks were written down in the associations agreement or Verbändevereinbarung (VV) in May 1998. Revised versions of the first VV were determined in December 1999 and December 2001. As already mentioned in the introduction, however, certain problems still seem to exist. In particular, complaints about excessive network access and transmission prices suggest that prices, at least in some cases, might be improperly inflated.

In order to detect excessive network usage prices, the "working group for electricity network utilization" has proposed to introduce the S-rule. In terms of our notation this means that the Bundeskartellamt wants to calculate the difference $S=p_{B}-r_{A}-c_{A}-v_{A}=p_{B}-m_{A}$. If this value is negative, it is concluded that $r_{A}$ is improperly inflated, while a nonnegative value indicates that $r_{A}$ is appropriate. Note that $S$ is the difference between $B$ 's final price and $A$ 's overall marginal costs. One might ask why instead of $S$ the balance is not based on the value of $p_{B}-r_{A}-c_{B}-v_{B}$. If this were the case, the S-rule could be seen as a kind of AreedaTurner-test which, however, is difficult to implement, since the network owner could always try to shuffle costs from the generation and retail division into the network division. The potential advantage of the S-rule is that, in priniciple, all determinants are observable. However, this does not mean that the S-rule does not entail any problems.

Especially, if the retail supply and/or procurement costs of the network owner are lower than the respective costs of the rival, it is possible that he will charge his customers a cost covering price which, however, leads to a negative value of $S$. This is possible, even if the price for network usage is appropriately set.

To see this, define $\Delta r=r_{A}-r_{B}, \Delta c=c_{A}-c_{B}$, and $\Delta v=v_{A}-v_{B}$. A positive $\Delta r$ indicates that the network usage price might be improperly inflated, while a $\Delta r$ close to zero suggests that the access price is appropriate. A positive $\Delta c(\Delta v)$ means that $A$ has a cost advantage with respect to electricity generation (retail supply), while a negative value states that $B$ has a cost advantage. 
Assume that the network usage price is appropriate, e.g., $\Delta r=0$, and the network owner is more efficient than his rival, e.g., $\Delta c+\Delta v<0$. Then, the value of $S$ is given by

$$
S^{*}=p_{B}^{*}-c_{A}-v_{A}-r_{A}=-\frac{2}{3}(\Delta c+\Delta v)+T,
$$

where the second equality follows from the assumption that the network usage price is appropriate. Straightforward calculations establish the following lemma:

Lemma 1 One has

$$
S^{*}<0 \Leftrightarrow m_{B}<m_{A}-\frac{3}{2} T
$$

Lemma 1 states that the value of $S$ is negative if the network owner is more efficient and the degree of product differention is not too large. Thus, the lemma shows that the S-rule can lead to mistakes. The network owner may be accused of abusing his dominant market position by charging an excessive network usage price, even if this is not the case (type II error). Of course, as long as the S-rule is not implemented, this has no consequences, and firm behavior is not affected.

\section{Pricing in presence of the subtraction rule}

Any antitrust enforcement institution is faced with costs in its effort to distinguish between "competitive" and "anticompetitive" behavior of firms. These costs include the direct costs of identifying firms which are considered to violate antitrust laws. However, these costs are likely to be small since relatively few firms are ever subject directly to antitrust sanctions. The main costs are caused by firms' responses and adaptations to antitrust rules, and the way how they affect prices, costs and innovation; see Joskow (2002, p. 97/98).

If a network owner is confronted with the conjecture of abusing his dominant market position, he will anticipate a possible costly investigation and the risk of a dissuasion or a serious fine. Perhaps he must also act on the assumption of suffering from bad press, thereby forfeiting his reputation. In order to avoid these inconveniences, it can be expected that in many cases the network owner will refrain from actions which abet the conjecture of abusing a dominant position.

In this section we analyze the pricing behavior of firms under the assumption that the Bundeskartellamt implements the S-rule, and violations are subject to sanctions. We assume that the sanctions are increasing linearly with the violation of the S-rule, e.g., if the Kartellamt observes $S<0$, the penalty will be $k|S|$ with $k>0$.

Note that $A$ 's profit function is not affected by the introduction of the S-rule. It is the same as in the situation, where a violation of the S-rule is not punished, e.g. given by (3) in Section 2. However, the new rule changes the profit function of the network owner, which now reads 


$$
\widetilde{\Pi}_{B}\left(p_{A}, p_{B}\right)=\left\{\begin{array}{cl}
\Pi_{B}\left(p_{A}, p_{B}\right) & \text { if } \quad s \geq 0 \\
\Pi_{B}\left(p_{A}, p_{B}\right)-k|S| & \text { if } \quad s<0
\end{array},\right.
$$

with $\Pi_{B}\left(p_{A}, p_{B}\right)$ given in (3). Since $S=p_{B}-m_{A}$, (10) can be written as

$$
\widetilde{\Pi}_{B}\left(p_{A}, p_{B}\right)=\left\{\begin{array}{ccc}
\Pi_{B}\left(p_{A}, p_{B}\right) & \text { if } & p_{B} \geq m_{A} \\
\Pi_{B}\left(p_{A}, p_{B}\right)+k\left(p_{B}-m_{A}\right) & \text { if } & p_{B}<m_{A}
\end{array} .\right.
$$

The S-rule changes the network owner's incentives. As can be seen from equation (11), quoting a lower price will be punished if this leads to a violation of the S-rule. Thus, setting a low price becomes costly for B. The strategic effects can be best described with help of the firms' reaction functions. While firm $A$ 's reaction function is still given by equation (4), $B$ 's reaction function changes. In order to calculate the latter one has to take into account that $B$ 's profit function has a downward kink at $p_{B}=m_{A}$. The kink produces a discrete jump of the marginal profit function at this point:

$$
\frac{\partial \widetilde{\Pi}_{B}}{\partial p_{B}}\left(p_{A}, p_{B}\right)=\left\{\begin{array}{ccc}
\frac{\partial \Pi_{B}}{\partial p_{B}}\left(p_{A}, p_{B}\right) & \text { if } & p_{B} \geq m_{A} \\
\frac{\partial \Pi_{B}}{\partial p_{B}}\left(p_{A}, p_{B}\right)+k p_{B} & \text { if } & p_{B}<m_{A}
\end{array} .\right.
$$

Lemma 2 The network owner's reaction function is given by

$$
\tilde{p}_{B}\left(p_{A}\right)=\left\{\begin{array}{cl}
p_{B}\left(p_{A}\right)+k T & \text { if } p_{A}<2 m_{A}-m_{B}-(2 k+1) T \\
m_{A} & \text { if } 2 m_{A}-m_{B}-(2 k+1) T \leq p_{A} \leq 2 m_{A}-m_{B} . \\
p_{B}\left(p_{A}\right) & \text { if } p_{A}>2 m_{A}-m_{B}
\end{array}\right.
$$

\section{Proof see Appendix}

With this result we are ready to prove the following proposition:

Proposition 1 There exists a uniqe price equilibrium $\left(\widetilde{p}_{A}^{*}, \widetilde{p}_{B}^{*}\right)$. With

$$
R_{1}=m_{A}-\left(2 k+\frac{3}{2}\right) T \quad \text { and } \quad R_{2}=m_{A}-\frac{3}{2} T
$$

the following holds: (1) If $m_{B}<R_{1}$, then

$$
\left(\widetilde{p}_{A}^{*}, \widetilde{p}_{B}^{*}\right)=\left(\frac{1}{3}\left(2 m_{A}+m_{B}\right)+\left(\frac{2}{3} k+1\right) T, \frac{1}{3}\left(2 m_{B}+m_{A}\right)+\left(\frac{4}{3} k+1\right) T\right) .
$$

The resulting balance $\widetilde{S}^{*}=\widetilde{p}_{B}^{*}-m_{A}$ is given by

$$
\widetilde{S}^{*}=\frac{2}{3}\left(m_{B}-m_{A}\right)+\left(2 k+\frac{3}{2}\right) T .
$$


Firms' profits are

$$
\left(\widetilde{\Pi}_{A}^{*}, \widetilde{\Pi}_{B}^{*}\right)=\left(\frac{\left(m_{B}-m_{A}+3 T+2 k T\right)^{2}}{18 T}, \frac{\left(m_{A}-m_{B}+3 T-2 k T\right)^{2}}{18 T}\right) .
$$

(2) If $R_{1} \leq m_{B} \leq R_{2}$, then

$$
\begin{gathered}
\left(\widetilde{p}_{A}^{*}, \widetilde{p}_{B}^{*}\right)=\left(m_{A}+\frac{T}{2}, m_{A}\right), \\
\widetilde{S}^{*}=m_{A},
\end{gathered}
$$

$$
\left(\widetilde{\Pi}_{A}^{*}, \widetilde{\Pi}_{B}^{*}\right)=\left(\frac{T}{8}, \frac{3}{4}\left(m_{A}-m_{B}\right)\right)
$$

(3) If $R_{2}<m_{B}$, then

$$
\begin{gathered}
\left(\widetilde{p}_{A}^{*}, \tilde{p}_{B}^{*}\right)=\left(p_{A}^{*}, p_{B}^{*}\right)=\left(\frac{1}{3}\left(2 m_{A}+m_{B}\right)+T, \frac{1}{3}\left(2 m_{B}+m_{A}\right)+T\right), \\
\widetilde{S}^{*}=\frac{2}{3}\left(m_{B}-m_{A}+\frac{3}{2} T\right),
\end{gathered}
$$

and

$$
\left(\widetilde{\Pi}_{A}^{*}, \widetilde{\Pi}_{B}^{*}\right)=\left(\Pi_{A}^{*}, \Pi_{B}^{*}\right)=\left(\frac{\left(m_{B}-m_{A}+3 T\right)^{2}}{18 T}, \frac{\left(m_{A}-m_{B}+3 T\right)^{2}}{18 T}\right) .
$$

\section{Proof see Appendix}

According to Proposition 1 three different types of equilibrium exist. Which one occurs depends on the network owner's marginal costs relative to those of $A$. If $\mathrm{B}$ 's costs are substantially lower than $A$ 's, e.g., $m_{B}<R_{!}$, his price will be so low that the S-rule is violated; see Figure 1.

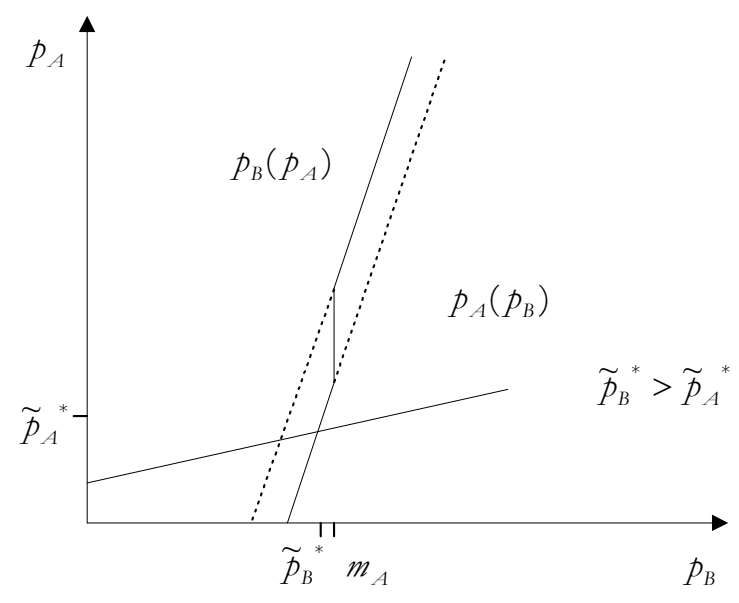

Figure 1: price equilibrium with S-rule being violated. 
The second type of equilibrium is depicted in Figure 2.

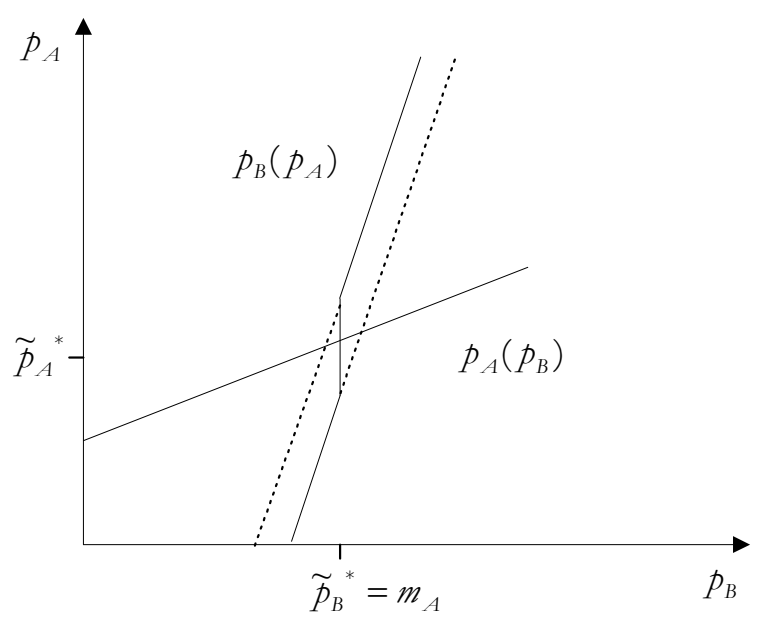

Figure 2: price equilibrium with S-rule being exactly fulfilled.

It occurs, if $\mathrm{B}$ 's costs are moderately lower than $A$ 's costs, e.g., if $R_{1} \leq m_{B} \leq R_{2}$. $A$ 's reaction curve then crosses $B$ 's reaction function in its flat segment. The network owner then chooses a price which exactly fulfills the S-rule. The third type of equilibrium is shown in Figure 3.

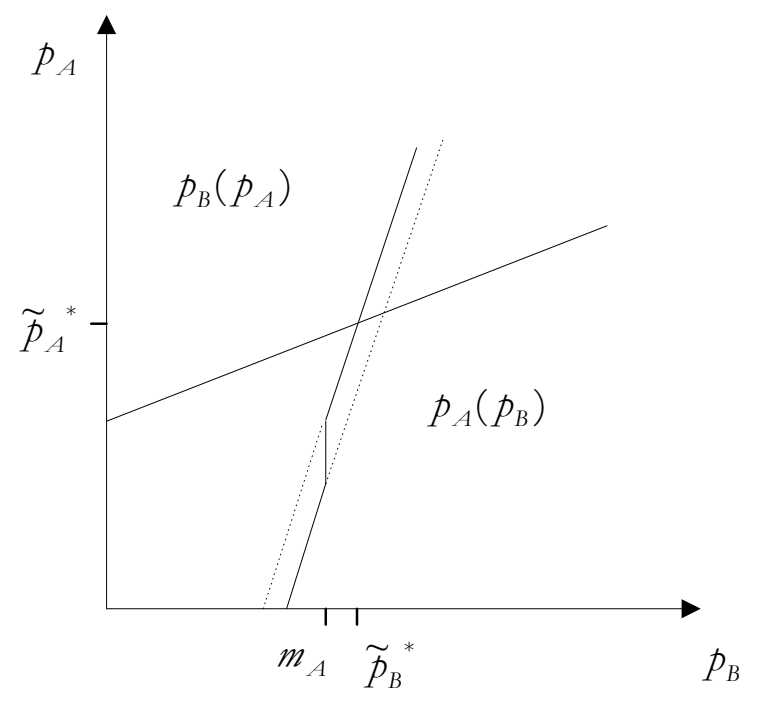

Figure 3: price equilibrium with S-rule being fulfilled.

In this case, $\mathrm{B}$ has only a small cost advantage or a cost disadvantage relative to $A$, e.g., $R_{2}<m_{B}$, and B's price does not violate the S-rule. Comparing the prices and profits in (5) and (7) with those stated in Proposition 1 leads to the following corollary: 
Corollary 1 If $m_{B}<R_{2}$, then the introduction of the S-rule will lead both firms to increase their price. Profits of both firms increase. If $m_{B} \geq R_{2}$, prices and profits will remain unchanged.

\section{Proof: see Appendix}

Note that $m_{B}<R_{2}$ is equivalent to $S^{*}<0$ (see Lemma 1). This means that in the absence of the $\mathrm{S}$-rule the network owner would set his price below $A$ 's marginal costs. If the S-rule is implemented, however, pricing below $A$ 's marginal costs would violate the S-rule, triggering a sanction. By increasing his price the network owner can reduce or avoid the sanction. When $\mathrm{B}$ increases his price, $A$ will follow suit, since reaction functions are upward sloping. Indeed, this is what will happen so that the introduction of the S-rule leads both firms to charge higher prices, making all consumers worse off. If $m_{B} \geq R_{2}$, the S-rule does not affect the firms" behavior. Since the network owner's price $p_{B}^{*}$ which prevailed before the introduction of the $\mathrm{S}$-rule does not violate it, $\mathrm{B}$ has no reason to change his price. Since $p_{A}^{*}$ is a best response to $p_{B}^{*}, A$ will also continue to charge the same price.

Note that a decrease in $T$ increases the boundaries $R_{1}$ and $R_{2}$; see equation (14). This means that a decrease in the degree of product differentiation enlarges the range of cost parameters $m_{B}$, where an implementation of the S-rule affects (e.g., increase) firms ' prices. An intuition for this result can be given as follows.

Notice that $\tilde{S}^{*}$ is influenced by $T$ and $m_{B}$ through B's price $\widetilde{p}_{B}^{*} \cdot$. As $\widetilde{p}_{B}^{*}$ is both increasing in $m_{B}$ and $T,{ }^{4}$ a lower value of $T$ allows a higher value of $m_{B}$ without changing the sign of $S^{*}$. But this is equivalent to shifting $R_{1}$ and $R_{2}$ to the right if $T$ decreases (see Figure 4).

\begin{tabular}{ccc}
$\mathrm{S}^{*}<0$ & $\mathrm{~S} *=0$ & $\mathrm{~S} * 0$ \\
\hline $\mathrm{R}_{1}$ & $\mathrm{R}_{2}$ & $m_{B}$
\end{tabular}

Figure 4: Parameter regions where the S-rule is violated, exactly fulfillded, fulfilled (but not exactly).

In the extreme case of homogeneous products and identical marginal costs, each firm sets its price equal to marginal costs. The balance $S^{*}$ then is zero so that the S-rule is exactly fulfilled. In the case, where the network owner's marginal costs are lower than those of his rival $A$, he sets a price slighty below $A$ 's marginal costs in order to win the whole market implying that the S-rule is slightly violated. On the other hand, if $A$ has lower marginal costs, $A$ wins the whole market, and the S-rule is not violated. With homogeneous goods the boundaries $R_{1}$ and $R_{2}$ are identical and equal to $m_{A}$.

The boundary $R_{1}$ shifts to the right if $k$ decreases. To understand this recall that $R_{1}$ delineates the region where $\mathrm{B}$ 's pricing behavior triggers a sanction (e.g., if $m_{B}<R_{1}$ ) from

\footnotetext{
${ }^{3}$ Recall, that $S^{*}=\widetilde{p}_{B}^{*}-m_{A}$.

${ }^{4}$ An increase in $T$ gives $\mathrm{B}$ more market power leading to a higher price.
} 
the zone where $\mathrm{B}$ 's price leads to an exact fulfillment of the S-rule (e.g., if $R_{1} \leq m_{B}<R_{2}$ ). The sanction is a cost element for B increasing its price. If the sanction becomes less severe, e.g., if $k$ decreases, higher values of $m_{B}$ are compatible with a negative value of $S^{*}$, and this is equivalent with $R_{1}$ shifting to the right if $k$ becomes smaller (see Figure 4). If $k$ goes to zero, $R_{1}$ approaches $R_{2}$, and in the limit conicides with $R_{2}$.

The boundary $R_{2}$ is independent of $k$. The reason is that on the parameter sets demarcated by $R_{2}$, B 's pricing behavior does not violate the S-rule and therefore, the fine parameter does not play any role in these regions.

\section{Alternative response strategies}

In Section 3 we have seen that the implementation of the S-rule changes the strategic situation between firms. We determined the price equilibrium $\left(\widetilde{p}_{A}^{*}, \widetilde{p}_{B}^{*}\right)$ in the modified game and showed that the network owner accepts the sanction if he has substantially lower marginal costs than his rival, e.g., if $m_{B}<R_{1}$ (see Proposition 1). It turned out that if the S-rule affects the firms' pricing, e.g., if $m_{B}<R_{2}$, prices will be higher than in the situation where the S-rule is not implemented (see Proposition 2).

In this section we analyze several alternative strategies, by which the network owner might respond to the introduction of the S-rule. The first (alternative) response strategy (RS) we wish to consider is:

RS 1 If the S-rule is implemented, B chooses a best response to $A$ 's price under the condition that the S-rule is not violated.

This strategy is based on the decision of the network owner to strictly avoid a confrontation with the cartel office. The objective is accomplished by increasing the price, if necessary, such that the new balance $S$ is no longer negative.

Proposition 2 Suppose that the network owner responds to the introduction of the S-rule according to RS-1. (1) If $m_{B}<R_{2}$, then prices will be given by

$$
\left(p_{A}^{1}, p_{B}^{1}\right)=\left(m_{A}+\frac{T}{2}, m_{A}\right)
$$

The resulting balance $S^{1}=p_{B}^{1}-m_{A}$ is equal to zero. Firms' profits are

$$
\left(\Pi_{A}^{1}, \Pi_{B}^{1}\right)=\left(\frac{T}{8}, \frac{3}{4}\left(m_{A}-m_{B}\right)\right)
$$

(2) If $m_{B} \geq R_{2}$, then prices and profits are the same as those given in part (3) of Proposition 1.

The proof is similar to that of Propositon 1 and therefore omitted. Figure 5a illustrates the first part of the propostition. Since at the formerly prevailing price $p_{B}^{*}$ the balance $S^{*}$ is negative, B will increase his price by $\Delta p_{B}=S^{*}$ so that B's new price is $p_{B}^{1}=m_{A}$. A 's best response to $m_{A}$ is $p_{A}^{1}=m_{A}+T / 2$. Given $\left(p_{A}^{1}, p_{B}^{1}\right)$, no further price change will occur. Firm $A$ has no 
incentive to deviate since his price is on his reaction curve. It is straightforward to verify that $\mathrm{B}$ has no incentive to increase his price further. Moreover, since B acts according to RS-1, he will not decrease his price, because this would violate the S-rule. The second part of Proposition 2 is shown in Figure 5b. In this case, the constraint of RS-1 is not binding so that firms choose mutual best responses.

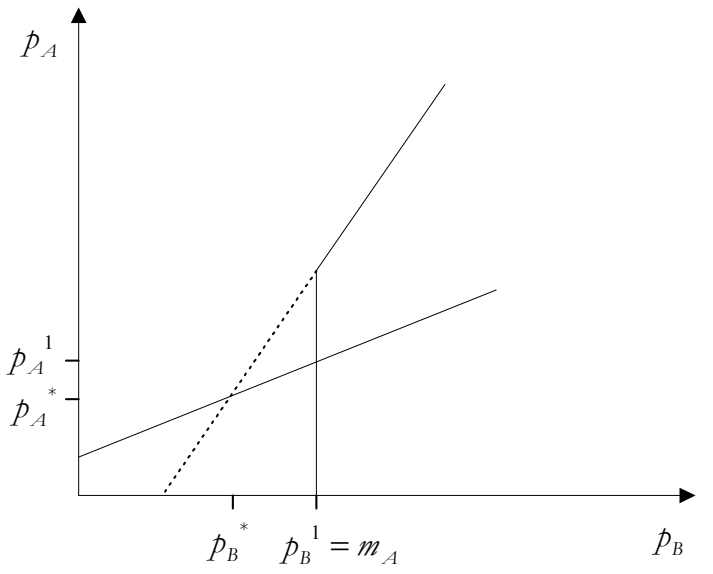

Figure 5a: price equilibrium with S-rule being violated.

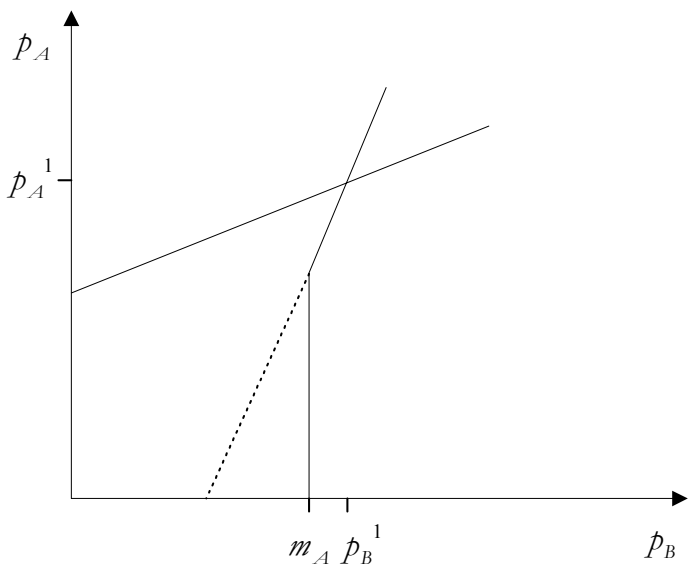

Figure $5 \mathrm{~b}$ : price equilibrium with S-rule being fulfilled.

Comparing prices and profits stated in Proposition 1 with those in Proposition 2 leads to the following corollary:

Corollary 2 If $m_{B}<R_{1}$, then $p_{i}^{1}>\widetilde{p}_{i}^{*}$ and $\Pi_{i}^{1}>\widetilde{\Pi}_{i}^{*}$, and if $m_{B} \geq R_{1}$, then $p_{i}^{1}=\widetilde{p}_{i}^{*}$ and $\Pi_{i}^{1}=\widetilde{\Pi}_{i}^{*}, i=A, B$.

Thus, if $\mathrm{B}$ has substantially lower marginal costs than $A$, e.g., if $m_{B}<\mathrm{R}_{1}$, then both prices and profits are higher than the respective values in (14) and (15). Indeed, this will be the case, regardless of whether the network usage fee is improperly inflated or not. The reason is that under RS-1, overall marginal costs of firm A act as a price floor for $\mathrm{B}$, which is binding if $m_{B} \leq R_{2}{ }^{5}$ Since $\mathrm{B}$ is better off by responding according to RS-1 (and also $A$ is better off), it should be expected that B will choose response strategy RS-1 instead of that described in Proposition 1.

Of course, the network owner could achieve a non-negative balance $S$ also by decreasing the network usage fee $r_{A}$, since this will reduce $A$ 's overall marginal costs $m_{A}$. This observation leads us to the second (alternative) response strategy we wish to consider:

RS-2 $S^{*}<0$, then B responds to the introduction of the S-rule by decreasing $r_{A}$ such that the S-rule is exactly fulfilled. To price changes of $A$, the network owner chooses a best response under the condition that the S-rule is not violated. If $S^{*} \geq 0, \mathrm{~B}$ leaves $r_{A}$ unchanged and continues to play $p_{B}^{*}$.

\footnotetext{
${ }^{5}$ Note that $m_{A}$ is not only binding if $m_{B}<R_{1}$, but also if $R_{1} \leq m_{B} \leq R_{2}$.
} 
Proposition 3 Suppose that the network owner responds to the introduction of the S-rule according to RS-2. (1) if $m_{B}<R_{2}$, then prices will be given by

$$
\left(p_{A}^{2}, p_{B}^{2}\right)=\left(p_{B}^{*}+\frac{T}{2}, p_{B}^{*}\right)
$$

where $p_{B}^{*}$ is given in (5). The resulting balance $S^{2}=p_{B}^{2}-m_{A}$ is equal to zero. Firms ' profits are

$$
\left(\Pi_{A}^{2}, \Pi_{B}^{2}\right)=\left(\frac{3}{8} T-\frac{m_{A}-m_{B}}{6}, \frac{3}{4} T+\frac{m_{A}-m_{B}}{4}\right) .
$$

(2) If $m_{B} \geq R_{2}$, then prices and profits are the same as those given in part (3) of Propostiion 1.

The proof is similar to that of Proposition 2 and therefore omitted. If $S^{*}<0$, the network will decrease the network price by $\Delta r_{A}=S^{*}=m_{A}-p_{B}^{*}$, which decreases $A$ 's marginal costs. With marginal costs $m_{A}-\Delta r_{A}, A$ 's best response to $p_{B}^{*}$ is $p_{B}^{*}+T / 2$. After this price change no further price change will occur. Firm $A$ has no incentive to deviate since its price is on its reaction curve. Given $p_{B}^{*}+T / 2, B$ has no incentive to increase his price above $p_{B}^{*}$. Moreover, B will not decrease his price, because this would violate the S-rule.

Comparing prices and profits described in Proposition 2 with those in Proposition 3 leads to the following corollary:

Corollary 3 If $m_{B}<R_{1}$, then $p_{i}^{1}>p_{i}^{2}$ and $\Pi_{i}^{1}>\Pi_{i}^{2}$, and if $m_{B} \geq R_{1}$, then $p_{i}^{1}=p_{i}^{2}$ and $\Pi_{i}^{1}=\Pi_{i}^{2}, i=A, B$.

Corollary 3 states that from B's point of view (and also from $A$ 's viewpoint) response strategy RS-1 is (weakly) better than RS-2. Again, this will be the case, regardless of whether the network usage fee is improperly inflated or not. Recall from Corollary 2 that profits resulting from RS-1 are also higher than those arising from the behavior prescribed in Proposition 1. Thus, since B is a profit maximizing firm, we can conclude that B will choose RS-1 if the Kartellamt introduces the S-rule. Accordingly, in order to determine the effects of the S-rule on the firms' pricing behavior we have to compare the prices stated in Proposition 2 with those in (7). The following Proposition contains the comparison of both prices and profits.

Proposition 4 Suppose that the Kartellamt introduces the S-rule Then, the following holds: (1) If $m_{B}<R_{2}$, then prices and profits of both firms will increase, e.g., $p_{i}^{1}>p_{i}^{*}$, and $\Pi_{i}^{1}>\Pi_{i}^{*}$. (2) If $m_{B} \geq R_{2}$, then prices and profits remain the same.

\section{Proof see Appendix}

Proposition 4 states that if the network owner's overall marginal costs is moderately or significantly lower than those of his rival, e.g., if $m_{B}<R_{2}$, then both firms will set higher prices than in the case, where the S-rule is not implemented. This will be the case, regardless 
of whether the network usage fee is improperly inflated or not. Thus, we arrive at a negative judgement of the S-rule.

The following reasoning points at a further weakness of the concept. Elberfeld and von Weizsäcker (2002) argue that the S-rule will always be misleading if the relevant cost elements, especially the procurement and retail supply costs, are miscalculated. The procurement costs cannot be simply registered by the stock market price. In the presence of long term contracts, the supplier will generate in many cases the power by himself. In this case, however, the relevant procurement costs are the variable average costs, which might be lower than the stock market price. The retail supply costs are predominantly considered as variable by the cartel office. However, the analysis of Elberfeld and von Weizsäcker (2002) reveals that these costs are to a high degree irreversible and fixed. Thus, the procedure of the cartel office leads to an overestimation of the true, and for the network owner's pricing decision relevant procurement and retail supply costs.

Finally, we wish to point out that the obtained results are not restricted to the electricity industry. In fact, they readily apply to any network based industry like gas and telecommunication.

\section{Conclusion}

In order to detect excessive network usage prices, the „working group electricity network utilization of the antitrust divisions of the federal republic and the states" proposed to introduce the S-rule. Under this rule the cartel office would calculate the difference between the network owner's price and overall marginal costs of the rival, including network access charges, which the competitor has to pay to the network owner. If this value is negative, it would be concluded that network access charges are improperly inflated. One problem of this rule is that the calculated value can be negative, even if the price for network usage is appropriately set. This outcome is most likely to occur, if the network owner is substantially more efficient than his rival. Since the network owner is punished if he violates the S-rule, the introduction of it changes his incentives. By increasing his price the network owner can reduce or avoid the sanction. If he increases his price, the rival will increase his price as well, since reaction functions are upward sloping. Indeed, this is what happens so that the introduction of the S-rule leads both firms to charge higher prices, making all consumers worse off. If the network owner has only a small efficiency advantage or is even less efficient than the rival, the S-rule does not affect the behavior of the firms. In this situation prices will be the same as before the introduction of the S-rule.

\section{References}

Elberfeld, W. and C. C. von Weizsäcker (2002), "Ist der Subtraktionstest ein geeignetes Verfahren zur Ermittlung missbräuchlich überhöhter Netznutzungsentgelte?", mimeo, University of Cologne.

Hotelling, H. H. (1929), “Stability in competition“, Economic Journal, vol. 39, pp. 41-57.

Joskow, P.(2002), "Transaction Cost Economics, Antitrust Rules and Remedies", Journal of Law, Economics and Organization“, Vol. 18, no. 1, pp. 95-116. 


\section{Appendix}

Proof of Lemma 2 We proceed in three steps. (1) If $p_{B}<m_{A}$, then the equations (3) and (11) imply that

$$
\left.\widetilde{\Pi}_{B}\left(p_{A}, p_{B}\right)=\left(p_{B}-m_{B}\right) \frac{1}{2}\left(1+\frac{p_{A}-p_{B}}{T}\right)+k\left(p_{B}-m_{A}\right)\right)
$$

Solving $\frac{\partial \widetilde{\Pi}_{B}}{\partial p_{B}}=0$ for $p_{B}$ gives

$$
\tilde{p}_{B}\left(p_{A}\right)=\frac{p_{A}+m_{B}+(2 k+1) T}{2}=p_{B}\left(p_{A}\right)+k T
$$

with $p_{B}\left(p_{A}\right)$ given in (4). $\widetilde{p}_{B}\left(p_{A}\right)$ is $\mathrm{B}$ 's reaction function as long as $\widetilde{p}_{B}\left(p_{A}\right)<m_{A}$. Since this inequality is equivalent to

$$
p_{A}<2 m_{A}-m_{B}-(2 k+1) T
$$

it follows that $\widetilde{p}_{B}\left(p_{A}\right)=p_{B}\left(p_{A}\right)+k T$ is B 's reaction function, if inequality (23) holds. (2) In a similar way one shows that if $p_{B}>m_{A}, \widetilde{p}_{B}\left(p_{A}\right)=p_{B}\left(p_{A}\right)$ is $\mathrm{B}$ 's reaction function if $2 m_{A}-m_{B}<p_{A}$. (3) It remains to be shown that $\tilde{p}_{B}\left(p_{A}\right)=m_{A}$ if

$$
2 m_{A}-m_{B}-(2 k+1) T \leq p_{A} \leq 2 m_{A}-m_{B}
$$

We show that for all $p_{A}$ satisfying the inequalities in (24) and for all $p_{B} \neq m_{A}$

$$
\widetilde{\Pi}_{B}\left(p_{A}, m_{A}\right)-\Pi_{B}\left(p_{A}, p_{B}\right)>0
$$

If $p_{B}<m_{A}$, (3) and (11) imply that

$$
\widetilde{\Pi}_{B}\left(p_{A}, m_{A}\right)=\left(m_{A}-m_{B}\right) \frac{1}{2}\left(1+\frac{p_{A}-p_{B}}{T}\right)
$$

while

$$
\Pi_{B}\left(p_{A}, m_{A}\right)=\left(p_{B}-m_{B}\right) \frac{1}{2}\left(1+\frac{p_{A}-p_{B}}{T}\right)+k\left(p_{B}-m_{A}\right) .
$$

It follows that (25) holds if and only if $p_{A}>m_{A}-m_{B}+p_{B}-(2 k+1) T$. This inequality is satisfied since, by assumption, $p_{B}<m_{A}$ and $p_{A}>2 m_{A}-m_{B}-(2 k+1) T$. If $p_{B}>m_{A}$, then (25) is equivalent to $p_{A}<m_{A}-m_{B}+p_{B}$. This inequality is holds, because $p_{B}>m_{A}$ and $p_{A}<2 m_{A}-m_{B}$

Proof of Proposition 1 The equilibrium is determined by the intersection of $A$ 's reaction function given in (4) with B's reaction function in (13). Since B's reaction function is flatter than (the inverse of) $A$ 's, and starts with higher values, it is clear that at most one equilibrium 
can exist. (1) $p_{A}\left(p_{B}\right)$ crosses the section of $\widetilde{p}_{B}\left(p_{A}\right)$ with values smaller than $m_{A}$, if and only if

$$
p_{A}\left(m_{A}\right)<2 m_{A}-m_{B}-(2 k+1) T
$$

(see also Figure 1). Since $p_{A}\left(m_{A}\right)=m_{A}+T / 2$, the inequality is equivalent to

$$
m_{B}<m_{A}-\left(2 k+\frac{3}{2}\right) T
$$

Solving $A$ 's reaction function for $p_{B}$ leads to $p_{B}=2 p_{A}-m_{A}-T$. The solution of

$$
\widetilde{p}_{B}\left(p_{A}\right)=\frac{p_{A}+m_{B}+(2 k+1) T}{2}=2 p_{A}-m_{A}-T
$$

gives the equilibrium price $\widetilde{p}_{A}^{*}=1 / 3\left(2 m_{A}+m_{B}\right)+\left(\frac{2}{3} k+1\right) T$. It follows that B's equilibrium price is $\tilde{p}_{B}^{*}=1 / 3\left(2 m_{B}+m_{A}\right)+(4 / 3 k+1) T$. (2) $p_{A}\left(p_{B}\right)$ intersects the constant part of $\widetilde{p}_{B}\left(p_{A}\right)=m_{A}$ if and only if

$$
m_{A}-\left(2 k+\frac{3}{2}\right) T \leq m_{B} \leq m_{A}-\frac{3}{2} T
$$

A's equilibrium price is the solution of

$$
\widetilde{p}_{B}\left(p_{A}\right)=m_{A}=2 p_{A}-m_{A}-T
$$

which is $\widetilde{p}_{A}^{*}=m_{A}+1 / 2 T$. (3) $p_{A}\left(p_{B}\right)$ crosses the part of $\widetilde{p}_{B}\left(p_{A}\right)$ with values larger than $m_{A}$, if and only if

$$
m_{A}-\frac{3}{2} T<m_{B}
$$

$A$ 's equilibrium price is the solution of

$$
\widetilde{p}_{B}\left(p_{A}\right)=\frac{p_{A}+m_{B}+T}{2}=2 p_{A}-m_{A}-T
$$

which is $\widetilde{p}_{A}^{*}=1 / 3\left(2 m_{A}+m_{B}\right)+T$. It follows that $B$ 's equilibrium price is $\widetilde{p}_{B}^{*}=1 / 3\left(2 m_{B}+m_{A}\right)+T$.

Proof of Corollary 1 (1) Suppose that $m_{B}<R_{1}$. Then, it is easily checked that for $i=A, B \widetilde{p}_{i}^{*}$ in (15) is greater than $p_{i}^{*}$ in (5), since $k>0$. Also, comparing the profits in (7) with those in (16) immediately shows that $\widetilde{\Pi}_{A}^{*}>\Pi_{A}^{*}$ and $\widetilde{\Pi}_{B}^{*}<\Pi_{B}^{*}$. (2) Assume that $R_{1} \leq m_{B} \leq R_{2}$. Comparing prices in (5) with those in (17) shows that both $\widetilde{p}_{A}^{*}<p_{A}^{1}$ and $\widetilde{p}_{B}^{*}<p_{B}^{1} \quad$ are equivalent to $m_{B}<R_{2}$. Next, observe that 
$\Pi_{A}^{*}=\left(m_{B}-m_{A}+3 T\right)^{2} /(18 T)<T / 8=\widetilde{\Pi}_{A}^{*} \Leftrightarrow m_{B}<m_{A}-3 / 2 T=R_{2}$, where the latter inequality is fulfilled by assumption. Thus, $A$ 's profits will be higher after the introduction of the S-rule. The same holds for B's profits. To see this, observe that

$$
\Pi_{B}^{*}-\widetilde{\Pi}_{B}^{*}=\frac{\left(3 T-\left(m_{A}-m_{B}\right)\right)^{2}}{18 T}-\frac{3}{4}\left(m_{A}-m_{B}\right)
$$

is decreasing in $m_{A}-m_{B}$. Thus, the difference is negative for all $m_{B}<m_{A}-3 / 2 T=R_{2}$, if it negative for $m_{B}=m_{A}-3 / 2 T$, or equivalently, for $m_{A}-m_{B}=3 / 2 T$. Substituting this value into (26) gives $\Pi_{B}^{*}-\widetilde{\Pi}_{B}^{*}=1 / 8 T-9 / 8 T<0$. (2) If $m_{B} \geq R_{2}$, the prices and profits described in Proposition 1 are the same as those given in Proposition 2.

Proof of Corollary 2 (1) Suppose that $m_{B}<R_{1}$. Comparing prices in (5) with those in (19) shows that both $\widetilde{p}_{A}^{*}<p_{A}^{1}$ and $\widetilde{p}_{B}^{*}<p_{B}^{1}$ are equivalent to $m_{B}<R_{2}$. The latter inequality is fulfilled since $m_{B}<R_{1}$ and $R_{1}<R_{2}$. Comparing profits in (16) with those in (20) reveals that $\widetilde{\Pi}_{A}^{*}<\Pi_{A}^{1}$ is equivalent to $m_{B}<R_{1}$, where the latter inequality is satisfied by assumption.

To prove that $\widetilde{\Pi}_{B}^{*}<\Pi_{B}^{1}$ it suffices to show that $\Pi_{B}^{*}<\Pi_{B}^{1}$, because $\widetilde{\Pi}_{B}^{*}<\Pi_{B}^{*} ; \Pi_{B}^{*}$ is given in (7). It can be easily checked that the inequality $\Pi_{B}^{*}<\Pi_{B}^{1}$ is equivalent to

$$
\frac{\left(3 / 2 T-m_{A}+m_{B}\right)\left(6 T-m_{A}+m_{B}\right)}{18 T}<0 .
$$

Note that $m_{A}-3 T<m_{B}{ }^{6}$ implies $m_{A}-3 T<m_{B}$ implies that $m_{A}-6 T<m_{B}$. Thus, (27) holds if and only if $3 / 2 T-m_{A}+m_{B}<0$, or equivalenty, if $m_{B}<R_{2}$. The latter inequality is fulfilled because $m_{B}<R_{1}$ (by assumption) and $R_{1}<R_{2}$ (by definition). (2) If $m_{B} \geq R_{1}$, the prices and profits given in Proposition 1 and 2 are the same.

Proof of Corollary 3 (1) Suppose that $m_{B}<R_{1}$. Comparing prices in (19) with those in (21) shows that both $p_{A}^{2}<p_{A}^{1}$ and $p_{B}^{2}<p_{B}^{1}$ are equivalent to $m_{B}<R_{2}$. Similarly, one has that $\Pi_{i}^{2}<\Pi_{i}^{1}, i=A, B$, is equivalent to $m_{B}<R_{2}$. (2) If $m_{B} \geq R_{1}$, the prices and profits the prices and profits given in Proposition 2 and 3 are identical.

Proof of Proposition 4 (1) Suppose that $m_{B}<R_{2}$. Comparing prices in (5) with those in (19) shows that both $p_{A}^{*}<p_{A}^{1}$ and $p_{B}^{*}<p_{B}^{1}$ are equivalent to $m_{B}<R_{2}$. Similarly, one has that $\Pi_{A}^{1}>\Pi_{A}^{*}$ is equivalent to $m_{B}<R_{2}$. Thus, A's profits will be higher after the introduction of the S-rule. The same holds for B's profits. To see this, observe that

$$
\Pi_{B}^{*}-\widetilde{\Pi}_{B}^{1}=\frac{\left(3 T-\left(m_{A}-m_{B}\right)\right)^{2}}{18 T}-\frac{3}{4}\left(m_{A}-m_{B}\right)
$$

\footnotetext{
${ }^{6}$ The inequality holds because we have assumed that both firms produce positive quantities in equilibrium.
} 
is decreasing in $m_{A}-m_{B}$. Thus, the difference is negative for all $m_{B}<m_{A}-3 / 2 T=R_{2}$, if it negative for $m_{B}=m_{A}-3 / 2 T$, or equivalently, for $m_{A}-m_{B}=3 / 2 T$. Substituting this value into (26) gives $\Pi_{B}^{*}-\widetilde{\Pi}_{B}^{1}=1 / 8 T-9 / 8 T<0$. (2) If $m_{B} \geq R_{2}$, the prices and profits described in Proposition 1 are the same as those given in Proposition 2. In the proof of Corollary 2 we showed that $\Pi_{B}^{1}>\Pi_{B}^{*}$ (2) If $m_{B} \geq R_{2}$, the prices and profits stated in (5) and (7) are the same as those stated in part (2) of Proposition 4. 